\title{
Análise Comparativa de Projetos Pedagógicos com Apoio da Tecnologia Móvel
}

\author{
Guilherme H. Souza ${ }^{1}$, Jaqueline F. Domenciano², ${ }^{2}$ Maicon Pires ${ }^{3}$ \\ ${ }^{1}$ Professor do Núcleo de Informação e Comunicação - Centro Paula Souza \\ Mestrando em Computação - Universidade Federal de São Carlos \\ ${ }^{2}$ Professora do Núcleo de Informação e Comunicação - Centro Paula Souza \\ Mestranda em Ciência, Tecnologia e Sociedade - Universidade Federal de São Carlos \\ ${ }^{3}$ Professor do Núcleo de Informação e Comunicação - Centro Paula Souza \\ Especialista em Computação Gráfica - Centro Universitário SENAC de Campinas \\ \{guilherme.souza, jaqueline.domenciano, maicon.pires\} detec.sp.gov.br
}

Este trabalho descreve o resultado de uma pesquisa sobre iniciativas de introdução da tecnologia móvel no ambiente escolar - m-learning. O objetivo central desta pesquisa é analisar iniciativas de m-learning e através delas, relacionar os principais elementos envolvidos no processo de ensino e aprendizagem, identificando metodologias eficazes para a implantação de tecnologias móveis no ambiente escolar.

Através de um levantamento bibliográfico foram identificadas algumas iniciativas no uso da tecnologia móvel como ferramenta para dinamizar o ensino. Para a análise, foram selecionados sete Projetos:

- Projeto PALMA: Programa de Alfabetização da língua materna

- Projeto de inserção de Tablets na Rede Pública de São Paulo

- OLPC - One Laptop per Children

- Seeds of Empowerment

- iPad na Sala de Aula

- Domus Mobile

- SchoolSenses@Internet.

Após análise e interpretação do material selecionado, foi construída uma tabela comparativa, que apresenta cada Projeto estudado de acordo com os objetivos, os métodos pedagógicos, os resultados alcançados e as características do hardware utilizado. Mesmo com focos diferenciados, os Projetos analisados mostraram a necessidade de um intenso planejamento para aliar tecnologia móvel ao projeto pedagógico. Alguns pontos fundamentais para a criação de projetos multidisciplinares com apoio da tecnologia móvel foram levantados: adaptação da estrutura física escolar, aquisição de equipamentos adequados (quantidade suficiente e configuração compatível com aplicativos utilizados), reflexão pedagógica (capacitar o professor para o uso da ferramenta e conscientizá-lo da necessidade de incluir as novas ferramentas de informação e comunicação no seu ambiente tradicional de ensino). 